\title{
A potential role for muscle in glucose homeostasis: in vivo kinetic studies in glycogen storage disease type 1a and fructose-1,6-bisphosphatase deficiency
}

\author{
Hidde H. Huidekoper • Gepke Visser • \\ Mariëtte T. Ackermans - Hans P. Sauerwein • \\ Frits A. Wijburg
}

Received: 11 September 2009 /Revised: 7 December 2009 /Accepted: 9 December 2009 / Published online: 2 February 2010

(C) The Author(s) 2010. This article is published with open access at Springerlink.com

\begin{abstract}
Background A potential role for muscle in glucose homeostasis was recently suggested based on characterization of extrahepatic and extrarenal glucose-6-phosphatase (glucose6-phosphatase- $\beta$ ). To study the role of extrahepatic tissue in glucose homeostasis during fasting glucose kinetics were studied in two patients with a deficient hepatic and renal glycogenolysis and/or gluconeogenesis.

Design Endogenous glucose production (EGP), glycogenolysis (GGL), and gluconeogenesis (GNG) were quantified with stable isotopes in a patient with glycogen storage disease type 1a (GSD-1a) and a patient with fructose-1,6-bisphosphatase (FBPase) deficiency. The $\left[6,6-{ }^{2} \mathrm{H}_{2}\right]$ glucose dilution method in combination with the
\end{abstract}

Communicated by: Jean-Marie Saudubray

Competing interest: None declared.

H. H. Huidekoper · F. A. Wijburg $(\bowtie)$

Department of Pediatrics (G8-205) Academic Medical Center, University Hospital of Amsterdam,

PO Box 22660 NL-1100 DD, Amsterdam, The Netherlands

e-mail: f.a.wijburg@amc.uva.nl

M. T. Ackermans

Department of Clinical Chemistry, Laboratory of Endocrinology,

University of Amsterdam,

Amsterdam, The Netherlands

H. P. Sauerwein

Department of Endocrinology \& Metabolism,

Academic Medical Center, University of Amsterdam,

Amsterdam, The Netherlands

G. Visser

Wilhelmina Children's Hospital,

University Medical Center Utrecht,

Utrecht, The Netherlands deuterated water method was used during individualized fasting tests.

Results Both patients became hypoglycemic after 2.5 and $14.5 \mathrm{~h}$ fasting, respectively. At that time, the patient with GSD-1a had EGP $3.84 \mu \mathrm{mol} / \mathrm{kg}$ per min $(30 \%$ of normal EGP after an overnight fast), GGL $3.09 \mu \mathrm{mol} / \mathrm{kg}$ per min, and GNG $0.75 \mu \mathrm{mol} / \mathrm{kg}$ per min. The patient with FBPase deficiency had EGP $8.53 \mu \mathrm{mol} / \mathrm{kg}$ per min $(62 \%$ of normal EGP after an overnight fast), GGL $6.89 \mu \mathrm{mol} / \mathrm{kg}$ per min GGL, and GNG $1.64 \mu \mathrm{mol} / \mathrm{kg}$ per min.

Conclusion EGP was severely hampered in both patients, resulting in hypoglycemia. However, despite defective hepatic and renal GNG in both disorders and defective hepatic GGL in GSD-1a, both patients were still able to produce glucose via both pathways. As all necessary enzymes of these pathways have now been functionally detected in muscle, a contribution of muscle to EGP during fasting via both GGL as well as GNG is suggested.
Abbreviations
EGP Endogenous glucose production
GGL Glycogenolysis
GNG Gluconeogenesis
GSD Glycogen storage disease
FBPase Fructose-1,6-bisphosphatase

\section{Introduction}

Endogenous glucose production (EGP) during fasting is predominantly derived from hepatic gluconeogenesis (GNG) and glycogenolysis (GGL), with a minor contribution from renal GNG (Ekberg et al. 1999). Recently, a potential additional role for muscle in EGP has been 
suggested based on characterization of an isoform of glucose-6-phosphatase, glucose-6-phosphatase- $\beta$ (Glc-6Pase- $\beta$ ) expressed in muscle and other extrahepatic tissue (Martin et al. 2002; Shieh et al. 2003). Gl-6-Pase- $\beta$ has been shown to have structural and functional properties in muscle comparable with glucose-6-phosphatase- $\alpha$ expressed in liver, kidney, and intestine (EC 3.1.3.9; Glc6-Pase- $\alpha$ ) (Shieh et al. 2004). As patients with glycogen storage disease 1a (GSD-1a; OMIM \#232200) are deficient for Glc-6-Pase- $\alpha$, resulting in defective hepatic and renal GNG and GGL, Gl-6-Pase- $\beta$ activity in muscle might explain the residual EGP previously observed in these patients (Kalhan et al. 1982; Schwenk et al. 1986; Tsalikian et al. 1984; Weghuber et al. 2007). In order to investigate the potential role of extrahepatic and extrarenal tissue in glucose homeostasis during fasting in vivo, we performed whole-body kinetic studies in a patient with GSD-1a and a patient with fructose-1,6-bisphosphatase (FBPase) deficiency (OMIM \#229700), an inborn error of hepatic and renal GNG. For the first time, differential contributions of GGL and GNG to EGP during fasting were quantified in these disorders using the $\left[6,6-{ }^{2} \mathrm{H}_{2}\right]$ glucose isotope dilution method combined with the deuterated water method (Landau et al. 1996; Wolfe et al. 2005).

\section{Materials and methods}

Study individuals

Patient 1 presented with severe hypoglycemia (plasma glucose $0.3 \mathrm{mmol} / \mathrm{L}$ ) and hepatomegaly at the age of 4 months. GSD-1a was diagnosed on the the basis of a complete deficiency of glucose-6-phosphatase activity in a fresh liver biopsy. This diagnosis was later confirmed by mutation analysis revealing two mutations known to completely abolish Glc-6-Pase- $\alpha$ activity (Table 1) (Rake et al. 2000). Patient 2 was admitted at 11 months because of convulsions due to hypoglycemia. At this time, she exhibited severe metabolic acidosis with hyperlactatemia and a marked hepatomegaly. She was diagnosed with FBPase deficiency by repeated demonstration of undetectable enzyme activity in leucocytes (Table 1) (Baker et al. 1970).

The in vivo stable isotope studies were approved by the Institutional Review Board. Both patients and their parents gave informed consent prior to the studies.

\section{Study protocol}

Fasting tests were performed at the age of 17.9 and of 16.7 years, respectively. Both patients were admitted 1 day before the test. An intravenous catheter was inserted into antecubital veins of both arms after topical application of lidocaine cream. One catheter was used to administer $\left[6,6-{ }^{2} \mathrm{H}_{2}\right]$ glucose and the other for blood sampling. At baseline, a blood sample was collected to determine background enrichment of deuterated water in plasma. Fasting was started at a time considered safe based on previous experience with fasting in the patients. Prior to fasting, both patients consumed their regular evening meal. Patient 1 received nocturnal nasogastric drip feeding without glucose polymers. This drip feeding was discontinued $2 \mathrm{~h}$ prior to initiation of $\left[6,6-{ }^{2} \mathrm{H}_{2}\right]$ glucose infusion and substituted by an unlabeled glucose infusion at a rate of $5 \mathrm{mg} / \mathrm{kg}$ per min, which was continued until the start of the $\left[6,6-{ }^{2} \mathrm{H}_{2}\right]$ glucose infusion. Both patients remained fasted throughout the test and maintained bed rest (Fig. 1).

Twelve hours prior to $\left[6,6-{ }^{2} \mathrm{H}_{2}\right]$ glucose infusion, both patients drank deuterium-enriched water (99\% pure; Cambridge Isotope Laboratories, Cambridge, MA, USA) at a dose of $5 \mathrm{~g} / \mathrm{kg}$ body water divided in five doses within 120 min (Ackermans et al. 2001). The total amount of body water $(\mathrm{kg})$ was estimated as $60 \%$ of body weight $(\mathrm{kg})$ (Friis-Hansen 1961). Thereafter, patients were only allowed to drink tap water enriched to $0.5 \%$ with deuterated water until the end of the test. At the start of the fasting test in patient 1 , after $10 \mathrm{~h}$ of fasting in patient 2 , and after collection of a blood sample to determine background enrichment of

Table 1 Patient characteristics

\begin{tabular}{|c|c|c|c|c|c|c|c|}
\hline & Sex & Age (years) & Height (m) & Weight (kg) & Inborn error of metabolism & Enzyme activity (normal range) & DNA analysis \\
\hline Patient 1 & M & 17.9 & $1.76(-1 \mathrm{SD})$ & $75.0(+1.5 \mathrm{SD})$ & $\begin{array}{l}\text { Glucose-6-phosphatase } \\
\text { deficiency (GSD Ia) }\end{array}$ & $0.0(10-30) \mathrm{nmol} / \mathrm{min} / \mathrm{mg}$ protein $^{\mathrm{a}}$ & $\mathrm{R} 170 \mathrm{X} \Delta \mathrm{F} 327^{\mathrm{b}}$ \\
\hline Patient 2 & $\mathrm{~F}$ & 16.7 & $1.50(-2 \mathrm{SD})$ & $60.0(+2 \mathrm{SD})$ & $\begin{array}{l}\text { Fructose-1,6- } \\
\text { bisphosphatase deficiency }\end{array}$ & $<0.1(3-20) \mathrm{nmol} / \mathrm{min} / \mathrm{mg} \operatorname{protein}^{\mathrm{c}}$ & ND \\
\hline
\end{tabular}

\footnotetext{
$N D$ not determined

${ }^{\text {a } I n}$ hepatocytes

${ }^{\mathrm{b}}$ Rake JP et al 2000

${ }^{\mathrm{c}}$ In leucocytes, repeated measurements; Baker L et al. 1970
} 
Fig. 1 Study protocols in patients 1 [glycogen storage disease type 1a (GSD-1a)] and 2 [fructose-1,6-bisphosphatase (FBPase)] deficiency
Patient 1 (GSD-1a)

glucose IV
$\left[6,6-{ }^{2} \mathrm{H}_{2}\right]$ glucose IV
blood sampling
fasting time (h)

$5 \mathrm{mg} / \mathrm{kg} \cdot \mathrm{min}$

bolus $(26.4 \mu \mathrm{mol} / \mathrm{kg})$

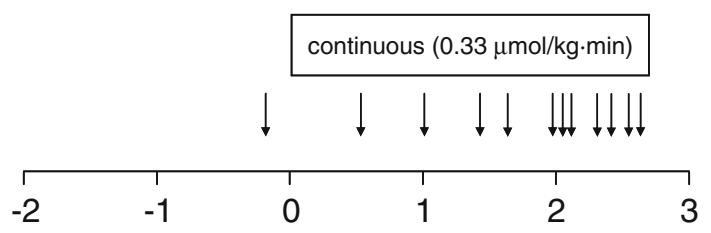

Patient 2 (FBPase deficiency)

$\left[6,6-{ }^{2} \mathrm{H}_{2}\right]$ glucose IV

blood sampling

fasting time $(\mathrm{h})$

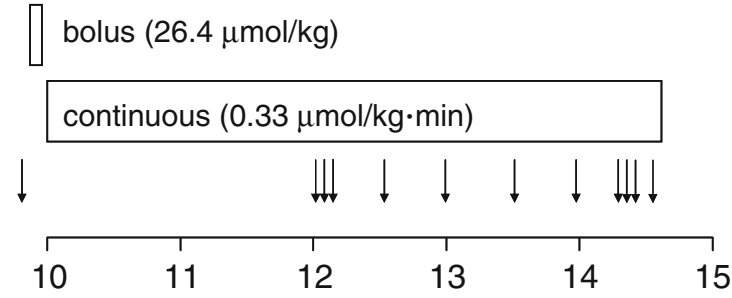

$\left[6,6-{ }^{2} \mathrm{H}_{2}\right]$ glucose in plasma, a primed continuous infusion of $\left[6,6-{ }^{2} \mathrm{H}_{2}\right]$ glucose $(99 \%$ pure; Cambridge Isotope Laboratories) was started (bolus $26.4 \mu \mathrm{mol} / \mathrm{kg}$; continuous infusion $0.33 \mu \mathrm{mol} / \mathrm{kg}$ per min) to reach an estimated $2 \%$ plasma enrichment (Bier et al. 1977). Blood samples were drawn every $5 \mathrm{~min}$ at the beginning and end of the test when patients became hypoglycemic, and every $30 \mathrm{~min}$ during the test (Fig. 1). Samples were centrifuged at $3,000 \mathrm{rpm}$ for $10 \mathrm{~min}$, after which plasma was collected and stored at $-20^{\circ} \mathrm{C}$. Blood samples to determine fractional GNG were immediately deproteinized by adding an equal amount of $10 \%$ perchloric acid. These samples were centrifuged at 4,000 rpm for $20 \mathrm{~min}$, after which the supernatant was collected and stored at $-20^{\circ} \mathrm{C}$. Blood glucose levels were monitored every hour and more frequently when glucose levels dropped $<3.5 \mathrm{mmol} / \mathrm{L}$. The test was terminated when clinical symptoms of hypoglycemia occurred, after which patients were immediately given carbohydrate-rich drinks and a meal.

Analytical methods

Plasma glucose concentration Plasma glucose levels were analyzed with the hexokinase method on a Roche MODULAR P800 analyzer (Roche Diagnostics GmbH, Mannheim, Germany).

Hormones Plasma insulin and cortisol concentrations were determined on an Immulite 2000 system (Diagnostic Products Corporation, Los Angeles, CA, USA). Insulin was measured with a chemiluminescent immunometric assay, and cortisol was measured with a chemiluminescent immuno assay. Glucagon was determined by RIA (Linco Research, St. Charles, MO, USA). Plasma free fatty acid (FFA) levels were measured by an enzymatic method (NEFAC; Wako Chemicals GmbH, Neuss, Germany).

Plasma $\left[6,6-^{2} \mathrm{H}_{2}\right]$ glucose enrichment Plasma glucose enrichments were determined as described previously (Ackermans et al. 2001). Briefly, plasma was deproteinized with methanol and evaporated to dryness. The extract was derivatized with hydroxylamine and acetic anhydride (Reinauer et al. 1990). The aldonitrile pentaacetate derivative of glucose was extracted into methylene chloride and evaporated to dryness. The extract was reconstituted in ethyl acetate and injected into a gas chromatograph/mass spectrometer (HP 6890 series GC system and 5973 Mass Selective Detector, Agilent Technologies, Palo Alto, CA, USA). Separation was achieved on a J\&W DB17 column $\left(30 \mathrm{~m} \times 0.25 \mathrm{~mm}, \mathrm{~d}_{f}\right.$ $0.25 \mu \mathrm{m} ; \mathrm{J} \& \mathrm{~W}$ Scientific, Folsom, CA). Glucose ions were monitored at $\mathrm{m} / \mathrm{z} 187,188$ and 189 . The isotopic enrichment of glucose was determined by dividing the peak area of $\mathrm{m} / \mathrm{z} 189$ by the peak area of $\mathrm{m} / \mathrm{z} 187$ after correction for background enrichment of $\left[6,6-{ }^{2} \mathrm{H}_{2}\right]$ glucose.

Deuterium enrichment in glucose at position C5 and in plasma water Glucose was converted to hexamethylene tetra-amine (Ackermans et al. 2001; Landau et al. 1996). Hexamethylene tetra-amine was injected into a gas chromatograph/ 
mass spectrometer (HP 6890 series GC system and 5973 Mass Selective Detector, Agilent Technologies). Separation was achieved on an AT-amine column $(30 \mathrm{~m} \times$ $0.25 \mathrm{~mm}, \mathrm{~d}_{f} 0.25 \mu \mathrm{m}$; Alltech Associates Inc, Deerfield, IL, USA). Hexamethylene tetra-amine ions were monitored at $\mathrm{m} / \mathrm{z} 140$ and 141. Deuterium enrichment in plasma was determined by a method adapted from Previs et al. (Previs et al. 1996).

\section{Calculations and statistical analysis}

Rate of glucose appearance The rate of glucose appearance in plasma $\left(\mathrm{R}_{\mathrm{a}}\right.$ glucose), reflecting whole-body endogenous glucose production (EGP) during fasting, was calculated with Steele's non-steady-state equation (Steele 1959). The fraction of the total extracellular glucose pool was assumed to be equal to the extracellular water compartment, which was between $20 \%$ and $25 \%$ of body weight in the patients studied (Friis-Hansen 1961). Calculated rates of EGP were compared to rates of EGP after overnight fasting in healthy individuals of the same age, as reported previously (Bier et al. 1977).

Absolute gluconeogenesis and glycogenolysis Absolute GNG was calculated by multiplying $\mathrm{R}_{\mathrm{a}}$ glucose by the fractional GNG. Fractional GNG was calculated as follows (Landau et al. 1996): $100 \%$ - (deuterium enrichment in glucose at position $\mathrm{C} 5 /$ deuterium enrichment in plasma water). Absolute GGL was calculated by subtracting absolute GNG from $\mathrm{R}_{\mathrm{a}}$ glucose.

\section{Results}

Plasma glucose, FFA, and glucoregulatory hormones

Plasma glucose In patient 1, after exogenous glucose supplementation was stopped, plasma glucose decreased from $6.3 \mathrm{mmol} / \mathrm{L}$ to $1.1 \mathrm{mmol} / \mathrm{L}$ within $2.5 \mathrm{~h}$ (Fig. 2). In patient 2, plasma glucose decreased from $3.7 \mathrm{mmol} / \mathrm{L}$ to $2.5 \mathrm{mmol} / \mathrm{L}$ at $12-14.5 \mathrm{~h}$ of fasting (Fig. 3).

Plasma FFA Plasma FFA concentration was $1.64 \mathrm{mmol} / \mathrm{L}$ in patient 1 and $2.16 \mathrm{mmol} / \mathrm{L}$ in patient 2 at the end of the test. This may have been inaccurate in patient 1 , as the hypertriglyceridemia could have interfered with the enzymatic assay.

Glucoregulatory hormones At the end of the test in both patients, plasma insulin levels were undetectable. Plasma glucagon was $190 \mathrm{ng} / \mathrm{L}$ in both patients, and plasma cortisol was $666 \mathrm{nmol} / \mathrm{L}$ in patient 1 and $792 \mathrm{nmol} / \mathrm{L}$ in patient 2.

Glucose kinetics

Patient 1 (GSD-1a) After $2 \mathrm{~h}$ of fasting, EGP was $5.09 \mu \mathrm{mol} / \mathrm{kg}$ per min, normal after an overnight fast $13.23 \mu \mathrm{mol} / \mathrm{kg}$ per min (Bier et al. 1977). The test was terminated at $2.6 \mathrm{~h}$ of fasting (EGP was $3.84 \mu \mathrm{mol} / \mathrm{kg}$ per min). GGL decreased from 4.39 to $3.09 \mu \mathrm{mol} / \mathrm{kg}$ per min between 2 and $2.6 \mathrm{~h}$ of fasting, representing 86.2 $80.5 \%$ of EGP, respectively. GNG was low but detectable: 0.60 and $0.78 \mu \mathrm{mol} / \mathrm{kg}$ per $\min (13.7-19.6 \%$ of EGP) at 2-2.6 h of fasting (Fig. 2).

Patient 2 (FBPase deficiency) After $12 \mathrm{~h}$ of fasting, EGP was $13.27 \mu \mathrm{mol} / \mathrm{kg}$ per $\mathrm{min}$, corresponding with the predicted EGP after an overnight fast for this age (13.77 $\mu \mathrm{mol} / \mathrm{kg}$ per min) (Bier et al. 1977). EGP decreased to $8.53 \mu \mathrm{mol} / \mathrm{kg}$ per min during the subsequent $2.5 \mathrm{~h}$ (14.5 $\mathrm{h}$ of fasting). At $12 \mathrm{~h}$ of fasting, GGL was $10.44 \mu \mathrm{mol} / \mathrm{kg}$ per min $(78.7 \%$ of EGP), decreasing to $6.88 \mu \mathrm{mol} / \mathrm{kg}$ per $\min (80.7 \%$ of EGP) during the subsequent $2.5 \mathrm{~h}$ of fasting. GNG was $2.83 \mu \mathrm{mol} / \mathrm{kg}$ per $\min (21.3 \%$ of EGP) at $12 \mathrm{~h}$ of fasting, decreasing to $1.65 \mu \mathrm{mol} / \mathrm{kg}$ per $\min (19.3 \%$ of EGP $)$ during the subsequent 2.5 h (Fig. 3).

\section{Discussion}

We report for the first time the contribution of both GGL and GNG to EGP during fasting in a patient with Glc-6Pase- $\alpha$ deficiency (GSD-1a) and a patient with FBPase deficiency. Our data on glucose kinetics show a persistent EGP from both GGL and GNG in both patients, despite their undetectable enzyme activities. On the basis of these results, a potential role of muscle in glucose homeostasis via both GGL and GNG in vivo is suggested. In patient 1 , Glc-6-Pase- $\alpha$ activity was completely deficient, which was confirmed by mutation analysis (Table 1) (Rake et al. 2000). This excludes any contribution from liver, kidney, or small intestine to EGP. However, EGP in this patient was still $30 \%$ of the predicted EGP in healthy individuals of the same age after an overnight fast (Bier et al. 1977). This is in line with previous studies showing residual EGP, even up to $60 \%$ of normal, in patients with GSD-1 (Kalhan et al. 1982; Schwenk et al. 1986; Tsalikian et al. 1984; Weghuber et al. 2007).

Three different explanations for the presence of EGP in GSD-1 have been proposed. First, it has been suggested that 
A

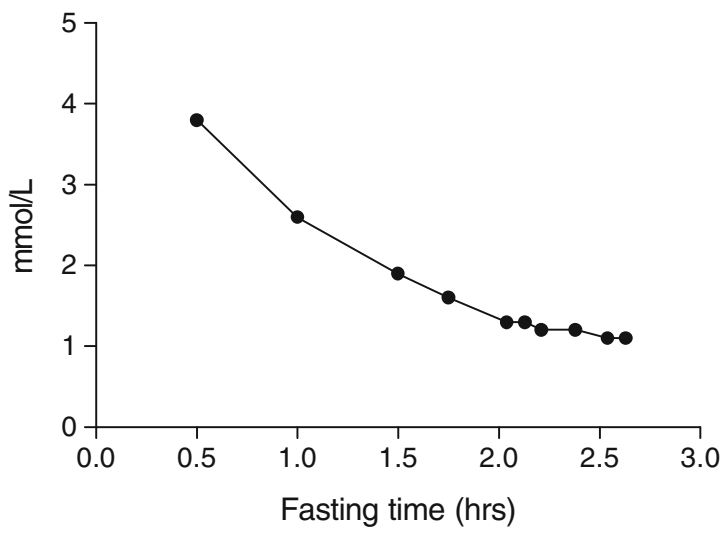

Fig. 2 Glucose kinetics in relation to plasma glucose concentration and fasting duration in a patient with glucose-6-phosphatase deficiency (GSD-1a). Plasma glucose concentrations are depicted

EGP is based on increased cycling through hepatic glycogen via action of amylo-1,6-glucosidase. However, this was ruled out by in vivo kinetic stable isotope studies (Rother et al. 1995). Second, EGP might be due to lysosomal digestion of hepatic glycogen through $\alpha$-1,4-glucosidase activity. However, this is very unlikely (Kalderon et al. 1989a; Tsalikian et al. 1984), as $\alpha$-1,4-glucosidase is not susceptible to substrate or hormonal regulation, and EGP in patients with GSD-1 is influenced by exogenous glucose supplementation (Schwenk et al. 1986; Tsalikian et al. 1984). Third, EGP in GSD-1 may be derived through muscular GGL and/or GNG. This hypothesis was made plausible by recent characterization of muscular Glc-6-Pase- $\beta$ (Shieh et al. 2003, 2004). Although Glc-6-Pase- $\beta$ has an approximately eightfold lower glucose6-phosphatase activity than Glc-6-Pase- $\alpha$ (Shieh et al. 2003), the ubiquitous expression of Glc-6-Pase- $\beta$ could still result in a significant cumulative glucose-6-phosphatase activity.

A

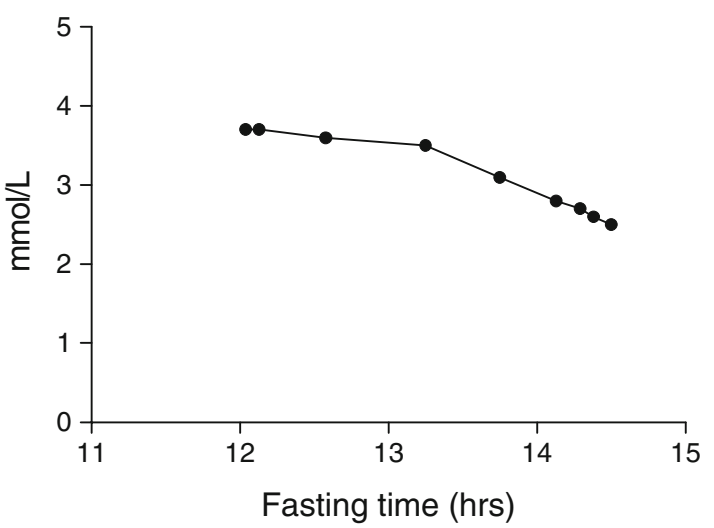

Fig. 3 Glucose kinetics in relation to plasma glucose concentration and fasting duration in a patient with fructose-1,6-bisphosphatase (FBPase) deficiency. Plasma glucose concentrations are depicted in
B

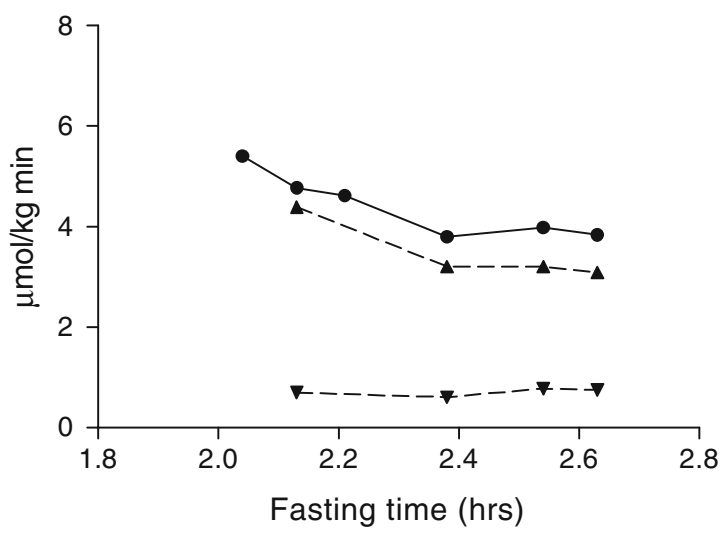

in the left panel (A). Endogenous glucose production (EGP; •), glycogenolysis (GGL; $\boldsymbol{\Delta}$ ) and gluconeogenesis (GNG; $\boldsymbol{\nabla}$ ) are depicted in the right panel (B)

The observed wide range in residual EGP between GSD-1a patients of the same age and with completely abolished enzyme activity, which is reflected by the interindividual differences in fasting tolerance in patients with GSD-1 (Kalderon et al. 1989b; Labrune et al. 1993; Moses 2002), may then be explained by differences in muscle mass and/or muscular glycogen content.

In the patient with GSD-1a studied by us, GGL contributed more than $80 \%$ to the observed EGP. In addition, GNG still contributed up to $19 \%$ to EGP in this patient (Fig. 2b). This contrasts with data from Kalderon et al., who excluded GNG as a source for EGP in GSD-1 based on a lack of carbon recycling from $\left[\mathrm{U}^{13}{ }^{13} \mathrm{C}\right]$ glucose (Kalderon et al. 1989a, b). Their method, however, only provides an indirect and nonquantitative assessment of GNG, whereas GNG determined with the deuterated water method, as used in our study, is a direct method to quantify

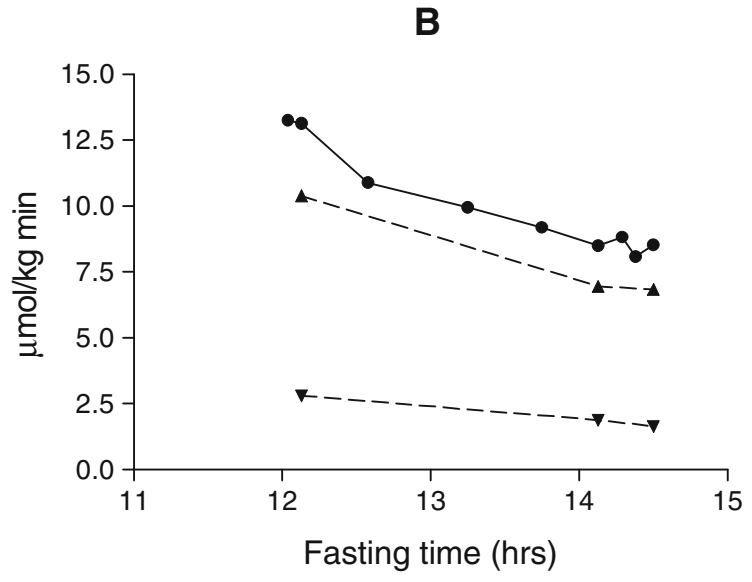

the left panel (A). Endogenous glucose production (EGP; •), glycogenolysis (GGL; $\boldsymbol{\Delta}$ ) and gluconeogenesis (GNG; $\boldsymbol{\nabla}$ ) are depicted in the right panel (B) 
GNG, yielding accurate results (Wolfe et al. 2005). Possibly, in experiments by Kalderon et al., the ${ }^{13} \mathrm{C}$ label from $\left[\mathrm{U}_{-}{ }^{13} \mathrm{C}\right]$ glucose was diluted beyond detection in the triose phosphate and oxaloacetate carbon pools (Kelleher 1986). The observed GNG may also be of muscular origin. Apart from Glc-6-Pase- $\beta$, a specific isoform of FBPase, another key enzyme in GNG, is functionally expressed in muscle (Tejwani 1983; Tillmann et al. 1998). Based on the formerly presumed lack of glucose-6-phosphatase activity in muscle, this muscle-specific FBPase was previously considered not to be involved in GNG (Adams et al. 1990; Dzugaj 2006). Alternatively, the observed residual EGP in the patient with GSD-1a might also be explained by renal GGL and/or renal and intestinal GNG, as Glc-6-Pase- $\beta$ is also expressed in kidney and small intestine (Martin et al. 2002). However, expression of Glc-6-Pase- $\beta$ is much lower in kidney and small intestine than in muscle (Martin et al. 2002) and has yet to been shown to be functionally active in these tissues. Furthermore, muscle has by far the largest body reservoir of glycogen (Shieh et al. 2004) and is therefore the most likely candidate tissue for extrahepatic and extrarenal glucose production.

A potential role for muscle in GNG is further supported by results of our study in the patient with liver- and kidneyspecific FBPase (EC 3.1.3.11) isoform deficiency. Although liver FBPase activity was not assayed and molecular investigation on the FBPase gene was not performed because, until now, only mixed results on disease-causing mutations have been reported in FBPase deficiency (Kikawa et al. 2002), the clinical presentation, in combination with repeated confirmation of absent FBPase activity in leucocytes, is highly suggestive of complete absence of liver- and kidney-specific FBPase isoform in patient 2. We detected that GNG still contributed up to $20 \%$ to EGP in this patient (Fig. 3). This might be explained by musclespecific FBPase isoform activity in combination with Glc6-Pase- $\beta$ activity.

It should be mentioned that a transaldolase exchange reaction may have contributed to deuterium labeling of glucose at position C5 (Landau et al. 1966). This would lead to an overestimation of gluconeogenesis as calculated from the ratio of deuterium labeling at glucose position C5 over deuterium labeling at glucose position $\mathrm{C} 2$. However, this alternative pathway cannot explain the results in the patient with GSD-1a, as functional hepatic glucose-6-phosphatase is still needed to release deuterium-labeled glucose in plasma. In addition, the contribution of this pathway to glucose C5 deuterium labeling in vivo remains to be determined, and therefore, the deuterated water method is currently one of the two best available methods to quantify gluconeogenesis and glycogenolysis in vivo (Bock et al. 2008).

Although we report a significant endogenous glucose production from gluconeogenesis and glycogenolysis in a patient with GSD-1a and a patient with FBPase deficiency, it should be noted that EGP in these patients was clearly not sufficient to maintain normoglycemia. Therefore, EGP originating from extrahepatic and extrarenal tissue can play only a minor role in glucose homeostasis in patients with defective hepatic and/or renal glucose production.

In conclusion, we provide in vivo evidence for both GNG and GGL contributing to EGP in GSD-1a. This, in combination with substantial residual GNG in FBPase deficiency, demonstrates an important role of extrahepatic and extrarenal tissue in glucose homeostasis. Our study strongly suggests a role of muscle in glucose homeostasis via both GGL and GNG.

Acknowledgements We thank Thessa Westphal and Klaske Honig for their technical assistance, and An Ruiter and Barbara Voermans for their excellent analytical support.

Open Access This article is distributed under the terms of the Creative Commons Attribution Noncommercial License which permits any noncommercial use, distribution, and reproduction in any medium, provided the original author(s) and source are credited.

\section{References}

Ackermans MT, Pereira Arias AM, Bisschop PH, Endert E, Sauerwein HP, Romijn JA (2001) The quantification of gluconeogenesis in healthy men by ${ }^{2} \mathrm{H}_{2} \mathrm{O}$ and $\left[2-{ }^{13} \mathrm{C}\right]$ glycerol yields different results: rates of gluconeogenesis in healthy men measured with ${ }^{2} \mathrm{H}_{2} \mathrm{O}$ are higher than those measured with $\left[2-{ }^{13} \mathrm{C}\right]$ glycerol. J Clin Endocrinol Metab 86:2220-2226

Adams A, Redden C, Menahem S (1990) Characterization of human fructose-1, 6-bisphosphatase in control and deficient tissues. J Inherit Metab Dis 13:829-848

Baker L, Winegrad AI (1970) Fasting hypoglycaemia and metabolic acidosis associated with deficiency of hepatic fructose-1, 6-diphosphatase activity. Lancet 2:13-16

Bier DM, Leake RD, Haymond MW et al (1977) Measurement of "true" glucose production rates in infancy and childhood with 6 , 6-dideuteroglucose. Diabetes 26:1016-1023

Bock G, Schumann WC, Basu R et al (2008) Evidence that processes other than gluconeogenesis may influence the ratio of deuterium on the fifth and third carbons of glucose: implications for the use of ${ }^{2} \mathrm{H}_{2} \mathrm{O}$ to measure gluconeogenesis in humans. Diabetes 57:50 55

Dzugaj A (2006) Localization and regulation of muscle fructose-1, 6-bisphosphatase, the key enzyme of glyconeogenesis. Adv Enzyme Regul 46:51-71

Ekberg K, Landau BR, Wajngot A et al (1999) Contributions by kidney and liver to glucose production in the postabsorptive state and after $60 \mathrm{~h}$ of fasting. Diabetes 48:292-298

Friis-Hansen B (1961) Body water compartments in children: changes during growth and related changes in body composition. Pediatrics 28:169-181

Kalderon B, Korman SH, Gutman A, Lapidot A (1989a) Estimation of glucose carbon recycling in children with glycogen storage disease: a ${ }^{13} \mathrm{C}$ NMR study using $\left[\mathrm{U}^{-1}{ }^{13} \mathrm{C}\right]$ glucose. Proc Natl Acad Sci U S A 86:4690-4694 
Kalderon B, Korman SH, Gutman A, Lapidot A (1989b) Glucose recycling and production in glycogenosis type I and III: stable isotope technique study. Am J Physiol 257:E346-E353

Kalhan SC, Gilfillan C, Tserng KY, Savin SM (1982) Glucose production in type I glycogen storage disease. J Pediatr 101:159-160

Kelleher JK (1986) Gluconeogenesis from labeled carbon: estimating isotope dilution. Am J Physiol 250:E296-E305

Kikawa Y, Shin YS, Inuzuka M, Zammarchi E, Mayumi M (2002) Diagnosis of fructose-1, 6-bisphosphatase deficiency using cultured lymphocyte fraction: a secure and noninvasive alternative to liver biopsy. J Inherit Metab Dis 25:41-46

Labrune P, Chalas J, Baussan C, Odievre M (1993) Tolerance to prolonged fasting in two children with type I glycogen storage disease. J Inherit Metab Dis 16:1044-1045

Landau BR, Bartsch GE (1966) Estimations of pathway contributions to glucose metabolism and the transaldolase reactions. J Biol Chem 241:741-749

Landau BR, Wahren J, Chandramouli V, Schumann WC, Ekberg K, Kalhan SC (1996) Contributions of gluconeogenesis to glucose production in the fasted state. J Clin Invest 98:378-385

Martin CC, Oeser JK, Svitek CA, Hunter SI, Hutton JC, O’Brien RM (2002) Identification and characterization of a human cDNA and gene encoding a ubiquitously expressed glucose-6-phosphatase catalytic subunit-related protein. J Mol Endocrinol 29:205222

Moses SW (2002) Historical highlights and unsolved problems in glycogen storage disease type 1. Eur J Pediatr 161(Suppl 1):S2-S9

Previs SF, Hazey JW, Diraison F, Beylot M, David F, Brunengraber H (1996) Assay of the deuterium enrichment of water via acetylene. J Mass Spectrom 31:639-642

Rake JP, ten Berge AM, Visser G et al (2000) Glycogen storage disease type Ia: recent experience with mutation analysis, a summary of mutations reported in the literature and a newly developed diagnostic flow chart. Eur J Pediatr 159:322330
Reinauer H, Gries FA, Hubinger A, Knode O, Severing K, Susanto F (1990) Determination of glucose turnover and glucose oxidation rates in man with stable isotope tracers. J Clin Chem Clin Biochem 28:505-511

Rother KI, Schwenk WF (1995) Glucose production in glycogen storage disease I is not associated with increased cycling through hepatic glycogen. Am J Physiol 269:E774-E778

Schwenk WF, Haymond MW (1986) Optimal rate of enteral glucose administration in children with glycogen storage disease type I. N Engl J Med 314:682-685

Shieh JJ, Pan CJ, Mansfield BC, Chou JY (2003) A glucose-6phosphate hydrolase, widely expressed outside the liver, can explain age-dependent resolution of hypoglycemia in glycogen storage disease type Ia. J Biol Chem 278:47098-47103

Shieh JJ, Pan CJ, Mansfield BC, Chou JY (2004) A potential new role for muscle in blood glucose homeostasis. J Biol Chem 279:26215-26219

Steele R (1959) Influences of glucose loading and of injected insulin on hepatic glucose output. Ann N Y Acad Sci 82:420-430

Tejwani GA (1983) Regulation of fructose-bisphosphatase activity. Adv Enzymol Relat Areas Mol Biol 54:121-194

Tillmann H, Eschrich K (1998) Isolation and characterization of an allelic cDNA for human muscle fructose-1, 6-bisphosphatase. Gene 212:295-304

Tsalikian E, Simmons P, Gerich JE, Howard C, Haymond MW (1984) Glucose production and utilization in children with glycogen storage disease type I. Am J Physiol 247:E513-E519

Weghuber D, Mandl M, Krssak M et al (2007) Characterization of hepatic and brain metabolism in young adults with glycogen storage disease type I. A magnetic resonance spectroscopy study, Am J Physiol Endocrinol Metab

Wolfe RR, Chinkes DL (2005) Glucose metabolism. In: Wolfe RR, Chinkes DL (eds) Isotope tracers in metabolic research: principles and practice of kinetic analysis. John Wiley \& Sons, Inc., Hoboken, pp 215-257 